\title{
Genetic diversity detection of seed-propagated walnut (Juglans regia L.) germplasm from Eastern Anatolia using SSR markers
}

\author{
Emine Orhan', Sadiye Peral Eyduran ${ }^{2}$, Danijela Poljuha ${ }^{3}$, Meleksen Akin ${ }^{2, *}$, \\ Tim Weber ${ }^{4}$ Sezai Ercisli ${ }^{5}$
}

\begin{abstract}
${ }^{1}$ Department of Agricultural Biotechnology, Agricultural Faculty, Ataturk University, 25240 Erzurum, Turkey ${ }^{2}$ Department of Horticulture, Agricultural Faculty, Igdir University, 76100 Igdir, Turkey

${ }^{3}$ Institute of Agriculture and Tourism, Karla Huguesa 8, 52440 Porec, Croatia

${ }^{4}$ Department of Life Sciences, Imperial College London, South Kensington Campus, London, SW7 2AZ UK

${ }^{5}$ Department of Horticulture, Agricultural Faculty, Ataturk University, 25240 Erzurum, Turkey
\end{abstract}

\begin{abstract}
Continuous seed propagation in Turkey has given rise to a great number of seedling walnut trees which represents valuable walnut genetic resources. The number of native walnut trees is estimated to be over 5 million in Turkey and they possess large phenotypic variability in yield, nut and kernel characteristics, late bud breaking, late flowering, winter hardiness and tolerance to diseases. Progress in walnut breeding requires the exploitation of genetic variation among cultivars and landraces. In this study, we used 32 local diverse walnut genotypes obtained from seeds and 2 standard cultivars ('Sebin' and 'Bilecik'). This study implemented 21 previously used simple sequence repeats (SSR) markers to determine genetic diversity. The analysis revealed 135 alleles with an average of 6.43 alleles per locus. Genetic similarity ranged from 0.23 (for samples KW22 and KW29) to 0.87 (for samples KW27 and KW28). The highest number of alleles per locus was obtained from WGA276 locus (11 alleles), followed by WGA054 (9 alleles), WGA202 and WGA321 (8 alleles) while the lowest number was detected in WGA027. According to the morphological and molecular data, the genotypes differed from each other and the cvs. Sebin and Bilecik. The majority of the genotypes had higher fruit weight and some of the genotypes had higher kernel ratio than cvs. Sebin and Bilecik implying the importance of registering genotypes as cultivars. This research provides information on the genetic relationship of walnut genotypes and cultivars and emphasises the importance of protection and utilisation of seed-propagated walnut genetic resources.
\end{abstract}

Keywords: genetic diversity, landraces, local genotypes, SSR

\section{INTRODUCTION}

Persian walnut (Juglans regia L.), a member of the family Juglandaceae, is the most important among 18 Juglans species. Walnut cultivation in Turkey has a long history, and almost every province in the country has important and diverse walnut population usually grown from seeds and found near river banks and agricultural areas as scattered trees similar to almond trees (Balci et al., 2001; Ercisli et al., 2012; Kirca et al., 2014).
Seed-propagated walnut trees have distinct morphological and phenological characteristics, in particular growth and bearing habit, tree vigour, bud break, kernel ratio and colour and nut weight, which are all highly variable (Sutyemez, 2006; Şimsek, 2010; Ertürk et al., 2014; Kirca et al., 2014). Commercial plantations of walnuts are relatively new to Turkey and are the result of programmes implemented by the 
Turkish government to encourage increasing walnut production. Successful commercial orchards were established in the last two decades mostly in the Aegean, Marmara, Southeastern Anatolia and Mediterranean regions, with both domestic and foreign cultivars. 'Chandler' is becoming the most popular cultivar, due to consumer preferences. However, it alone cannot meet the demands for high-quality walnuts in Turkey (Keles et al., 2014). The introduced cultivars such as Chandler did not adapt well to different agricultural regions in Turkey (Keles et al., 2014). On the other hand, in Turkey, non-grafted walnut seedlings had also been used in new walnut plantations. This has provided the opportunity to select the best genotypes from natural populations for good yield and nut quality characteristics. Yalova-1, Yalova-2, Yalova-3 and Yalova-4 as well as Sebin and Bilecik were the first Turkish walnut cultivars to be selected from natural walnut populations in different regions in Turkey (Olez, 1976). The Maras-18 cultivar is selected from Kahramanmaraş province in Turkey with a higher yield and better quality nuts than the mentioned cultivars and it presents homogamy in flowering (Sutyemez, 1998). Kaman-1 is another cultivar selected from natural population in inner Anatolia with a high yield and good nut characters. The Maras-18, Şebin and Bilecik cultivars are currently preferred in areas with short vegetation periods due to their early leafing time (Keles et al., 2014).

The main contributions of seed-propagated genotypes to plant breeding have been traits for more efficient nutrient uptake and utilisation, as well as useful genes for adaptation to stressful environments such as water stress, salinity and high temperatures. Seedpropagated walnut genotypes are generally adapted to local environment better than introduced cultivars (Keles et al., 2014). With the continued cycles of local planting, harvesting and farmers' selection, over time, genotypes will be selected for local environmental and agroecosystem conditions and practices, just as ecotypes of wild species are adapted to the local environmental conditions. Seed-propagated genotypes are adapted to their growing conditions and they possess adaptive complexes associated with the special conditions of cultivation, pure-stand associations, harvesting and other factors (Bennett, 1970; Villa et al., 2006).

The walnut tree is characterised by differentiation, adoption and a long history of cultivation throughout the temperate regions of the world. Due to these characteristics, it has formed a wide genetic diversity under appropriate environmental conditions (Martinez et al., 2010). However, there is only limited research on the identification of this extensive diversity and differentiation in seed-propagated walnut germplasm.

China is the world leader in walnut production (accounting for 50\% of the total) with 1,060,000 metric tons of walnut production annually, followed by the USA. The European Union, Ukraine, Chile, Turkey and Moldova are the other top regions/countries in walnut production (FAO, 2018). According to the agricultural statistics, there are 17,000,000 trees on 93,000 ha in Turkey corresponding to 210,000 tons of walnut production.

Identifying walnut genotypes and determining genetic relationships are necessary for registering genotypes as cultivars (Ercisli et al., 2012; Keles et al., 2014; Kirca et al., 2014). The traditional identification method by examining morphological features requires skilled professionals, which corresponds to the cost of genetic analysis. Furthermore, the approach is timeconsuming and laborious, and it depends on the season (Ercisli et al., 2008; Guney et al., 2018). Conversely, DNA molecular marker technology can be used without the influence of environmental conditions and is relatively quick, inexpensive and extremely accurate in identifying varieties (Eyduran et al., 2016; Poczai et al., 2013). The technology has been widely applied in the analysis of genetic diversity, variety identification and establishment of fingerprints in various fruit trees (Ercisli et al., 2008; 2011; Sutyemez, 2006; Guney et al., 2019). Various types of molecular markers have been widely applied in walnut genetic diversity studies. Random amplification of polymorphic DNA (RAPD) (Dogan et al., 2014), simple sequence repeats (SSRs) (Foroni et al., 2007; Karimi et al., 2010; Chen et al., 2014; Bernard et al., 2018; Khokhlov et al., 2018), intersimple sequence repeat amplification (ISSR) (Potter et al., 2002), amplified fragment length polymorphism (Kafkas et al., 2005; Bayazit et al., 2007) and single nucleotide polymorphism (SNP) analysis (Ciarmiello et al., 2011) were utilised in examining genetic variability and identity of walnut germplasm resources.

Recently, genome and transcriptome analysis had been done on J. regia. Persian walnut (J. regia) genome sequence was obtained from the cultivar Chandler to discover target genes and additional unknown genes. The walnut genome sequence provides important tools and methods to accelerate breeding and to facilitate the genetic dissection of complex traits. In addition, next-generation sequencing (NGS) of transcriptomes has proved an attractive alternative to whole genome sequencing. The transcriptome analysis of $J$ regia provided information on gene expression, gene regulation and amino acid content of proteins. The obtained sequence data were used to develop ESTderived SSR markers in J. regia, and EST-SSR markers and transcriptomic resources are found useful for future studies of population genetic structure, evolutionary ecology and breeding of J. regia and other Juglans species (Dang et al., 2016; Martinez-Garcia et al., 2016).

In Turkey, particularly in eastern Anatolia region, walnut production is still carried out using seedpropagated genotypes. Thus, walnut fruits in the market are mixture of fruits from various trees. Therefore, walnut industry and consumers are challenged in getting products of standard quality. Further breeding investigations on different seed-propagated walnut trees are required for selection of genotypes with high yield and quality. The success of breeding programmes depends mainly on the available genetic information 
Table 1. Some important morphological traits of walnut genotypes

\begin{tabular}{|c|c|c|c|c|c|c|c|}
\hline Genotypes & Growth habit & Bearing habit & Tree vigour & Bud break & Nut weight (g) & Kernel ratio $(\mathrm{g})$ & Kernel colour \\
\hline KW1 & Semi upright & Lateral & Medium & Late & 9.28 & 51.4 & Light amber \\
\hline KW2 & Spreading & Intermediate & Medium & Late & 10.25 & 47.6 & Light \\
\hline KW3 & Upright & Lateral & Strong & Mid Early & 10.86 & 56.4 & Light \\
\hline KW4 & Semi upright & Lateral & Medium & Early & 8.76 & 55.3 & Light \\
\hline KW5 & Spreading & Intermediate & Strong & Late & 12.43 & 48.7 & Light amber \\
\hline KW6 & Semi upright & Lateral & Medium & Late & 11.78 & 62.5 & Light \\
\hline KW7 & Semi upright & Lateral & Medium & Early & 9.05 & 59.3 & Light \\
\hline KW8 & Spreading & Lateral & Medium & Mid Early & 13.20 & 48.3 & Light amber \\
\hline KW9 & Upright & Lateral & Weak & Late & 12.56 & 45.3 & Light amber \\
\hline KW10 & Semi upright & Lateral & Medium & Late & 8.94 & 59.9 & Light \\
\hline KW11 & Spreading & Lateral & Strong & Early & 11.46 & 55.9 & Light \\
\hline KW12 & Semi upright & Intermediate & Medium & Late & 9.44 & 56.9 & Light amber \\
\hline KW13 & Upright & Lateral & Weak & Early & 11.28 & 53.4 & Light \\
\hline KW14 & Semi upright & Lateral & Strong & Late & 11.67 & 60.4 & Light amber \\
\hline KW15 & Spreading & Lateral & Strong & Mid Early & 9.60 & 62.3 & Light \\
\hline KW16 & Semi upright & Lateral & Medium & Early & 12.54 & 43.8 & Light \\
\hline KW17 & Upright & Lateral & Medium & Late & 10.89 & 47.3 & Very light \\
\hline KW18 & Semi upright & Intermediate & Medium & Mid Early & 9.76 & 60.1 & Light amber \\
\hline KW19 & Spreading & Lateral & Medium & Late & 9.28 & 51.4 & Light amber \\
\hline KW20 & Spreading & Lateral & Strong & Early & 10.20 & 42.8 & Very light \\
\hline KW21 & Spreading & Lateral & Medium & Late & 11.55 & 61.8 & Light \\
\hline KW22 & Semi upright & Lateral & Medium & Late & 9.09 & 50.6 & Light amber \\
\hline KW23 & Semi upright & Intermediate & Weak & Early & 9.33 & 51.0 & Light \\
\hline KW24 & Semi upright & Lateral & Medium & Late & 12.44 & 56.3 & Light \\
\hline KW25 & Upright & Intermediate & Strong & Early & 9.80 & 55.0 & Light amber \\
\hline KW26 & Semi upright & Lateral & Medium & Late & 10.50 & 44.4 & Light amber \\
\hline KW27 & Semi upright & Lateral & Strong & Mid Early & 9.15 & 52.7 & Light \\
\hline KW28 & Spreading & Lateral & Strong & Early & 11.75 & 50.0 & Light \\
\hline KW29 & Semi upright & Lateral & Medium & Early & 10.80 & 57.0 & Light amber \\
\hline KW30 & Semi upright & Lateral & Medium & Late & 12.65 & 48.1 & Light \\
\hline KW31 & Semi upright & Lateral & Medium & Late & 9.28 & 51.4 & Light amber \\
\hline KW32 & Upright & Intermediate & Weak & Early & 8.88 & 52.5 & Light \\
\hline Sebin & Semi upright & Lateral & Medium & Late & 11.80 & 58.9 & Light amber \\
\hline Bilecik & Semi upright & Lateral & Medium & Late & 9.19 & 51.4 & Light amber \\
\hline
\end{tabular}

of the breeding material. In addition, fast and accurate identification of genotypes and evaluation of the genetic variability provide substantial benefits for the certification of cultivars with specific characteristics. In this study, SSR markers were used to analyse the genetic relationships of seed-propagated walnut genotypes and to reveal their genetic diversity at molecular level.

To our knowledge, this is the first study on SSR analysis of seed-propagated walnuts grown in Eastern Anatolia region of Turkey. Therefore, the objectives of this research were to characterise and evaluate the genetic diversity of 32 seed-propagated walnut genotypes and 2 standard cultivars using SSR markers and to develop strategies for preserving endangered genetic resources of this species.

\section{MATERIALS AND METHODS}

\section{Plant material}

In total, 32 seed-propagated walnut genotypes along with 2 standard cultivars ('Sebin' and 'Bilecik') from
Kagizman district of Eastern Anatolia region in Turkey (Table 1) were analysed using SSR markers. Two standard cultivars ('Sebin' and 'Bilecik') were previously selected among seed-propagated walnut genotypes. Kagizman district has a narrow geographic range of longitude $\left(40^{\circ} 14 \mathrm{~N}-43^{\circ} 11 \mathrm{E}\right)$ located in Aras valley of eastern Turkey. In this valley, walnut populations consist of old walnut trees from open pollinated seedlings (70to 120-year-old trees). First, the mature seedling trees origin was labelled based on their region area $(\mathrm{KW} 1$ to KW32). The selected genotypes were healthy and had a full crop. Growth habit, bearing habit, tree vigour, bud break, nut weight, kernel ratio and kernel colour were determined (Table 1). Each genotype (KW1 to KW32) was presented by one seed-propagated tree. The trees cultivated in the valley represent the local population (seedlings) that were randomly planted by humans or birds. The ones with better yield and fruit characteristics among these walnut trees were selected and kept by the people, and they were considered as endangered genetic diversity because they were propagated by seeds. Growth 
habit, bearing habit, tree vigour and bud break were determined according to IPGRI (1994) in 2016. During harvest season, 50 nuts from each tree were randomly collected and evaluated for nut characteristics (weight, kernel percentage and kernel colour). The weights of nut and kernel were measured using an electronic balance with $0.01 \mathrm{~g}$ precision. Kernel percentage was estimated using formulas 'kernel weight/nut weight $\times$ 100' (Eriksson, 1998).

\section{DNA extraction}

Genomic DNA was extracted from young leaf tissues using the Wizard Genomic DNA Purification Kit (Promega, Madison, WI, USA) according to the instructions provided by the manufacturer. Subsequently, an RNAse treatment was performed to the eluted DNA samples. Purity and concentration of the DNA were confirmed both on $1 \%(\mathrm{w} / \mathrm{v})$ agarose gels and by NanoDrop ND-1000 Spectrophotometer.

\section{SSR analysis}

A total of 21 SSR loci were used (Table 2). Polymerase chain reaction (PCR) was conducted in a volume of $10 \mathrm{~mL}$, containing $15 \mathrm{ng}$ genomic DNA, 5 pmol of each primer, $0.5 \mathrm{mM}$ dNTP, 0.5 unit GoTaq DNA polymerase (Promega) and $1.5 \mathrm{mM} \mathrm{MgCl}_{2}$. The forward primers were 'labelled' with WellRED fluorescent dyes D2 (black), D3 (green) and D4 (blue) (Proligo, Paris, France). Reactions without DNA were included as negative controls. PCR amplification was performed using the Biometra PCR System. The amplification conditions consisted of an initial denaturation step of $3 \mathrm{~min}$ at $94^{\circ} \mathrm{C}$, followed by 35 cycles of $1 \mathrm{~min}$ at $94^{\circ} \mathrm{C}, 1 \mathrm{~min}$ at $52^{\circ} \mathrm{C}-56^{\circ} \mathrm{C}$ and $2 \mathrm{~min}$ at $72^{\circ} \mathrm{C}$ with a final extension at $72^{\circ} \mathrm{C}$ for $10 \mathrm{~min}$. The PCR products were run on CEQTM 8800 XL Capillary Genetic Analysis System (Beckman Coulter, Fullerton, CA) to determine polymorphisms. The analyses were repeated at least twice to ensure reproducibility of the results.

\section{Data analysis and genetic relationships}

The genetic analysis software 'IDENTITY' 1.0 (Wagner and Sefc, 1999) was used according to Paetkau et al. (1995) for the calculation of number of alleles $(n)$ and expected and observed heterozygosities ( $H_{\mathrm{e}}$ and $H_{\mathrm{o}}$, respectively). MICROSAT software (version 1.5) (Minch et al., 1995) was used for the determination of genetic similarity using proportion of the shared alleles, as described by Bowcock et al. (1994). The results were then converted to a similarity matrix and used to construct a dendrogram using the UPGMA method (Sneath and Sokal, 1973) and the software NTSYS-pc (Numerical Taxonomy and Multiware Analysis System, version 2.0) based on Dice similarity coefficients (Nei and Li, 1979) calculated using bootstrap analysis with 1,000 replications and FREETREE program (version 0.9.1.50) (Pavlicek et al., 1999). Polymorphic information content (PIC) was calculated according to Kalinowski et al. (2007). The principal component analysis (PCA) was performed to show the genetic variation of walnut genotypes/cultivars in a two-dimensional array of eigenvectors using the DCENTER and EIGEN modules of NTSYS-pc.

Table 2. SSRs, number of detected alleles, observed heterozygosity $\left(H_{\mathrm{o}}\right)$, expected heterozygosity $\left(H_{\mathrm{e}}\right)$ and PIC of 21 SSR markers on 32 walnut genotypes and 2 standard cultivars investigated

\begin{tabular}{llcccc}
\hline SSR primers & References & Number of alleles $(n)$ & Observed heterozygosity $\left(H_{\mathrm{o}}\right)$ & Expected heterozygosity $\left(H_{\mathrm{e}}\right)$ & PIC \\
\hline WGA001 & Dangl et al. (2005) & 7 & 0.47 & 0.58 & 0.67 \\
WGA004 & Woeste et al. (2002) & 5 & 0.64 & 0.60 & 0.55 \\
WGA005 & Woeste et al. (2002) & 6 & 0.80 & 0.71 & 0.77 \\
WGA009 & Dangl et al. (2005) & 6 & 0.47 & 0.49 & 0.68 \\
WGA027 & Woeste et al. (2002) & 3 & 0.55 & 0.67 & 0.72 \\
WGA032 & Woeste et al. (2002) & 8 & 0.80 & 0.60 & 0.75 \\
WGA054 & Woeste et al. (2002) & 9 & 0.53 & 0.60 & 0.58 \\
WGA069 & Woeste et al. (2002) & 7 & 0.71 & 0.49 & 0.64 \\
WGA071 & Woeste et al. (2002) & 4 & 0.52 & 0.64 & 0.69 \\
WGA072 & Woeste et al. (2002) & 5 & 0.74 & 0.53 & 0.60 \\
WGA079 & Woeste et al. (2002) & 4 & 0.58 & 0.71 & 0.55 \\
WGA089 & Dangl et al. (2005) & 5 & 0.62 & 0.80 & 0.79 \\
WGA118 & Dangl et al. (2005) & 5 & 0.58 & 0.63 & 0.65 \\
WGA202 & Dangl et al. (2005) & 8 & 0.70 & 0.64 & 0.83 \\
WGA225 & Dangl et al. (2005) & 5 & 0.41 & 0.58 & 0.62 \\
WGA276 & Dangl et al. (2005) & 11 & 0.39 & 0.60 & 0.85 \\
WGA321 & Dangl et al. (2005) & 8 & 0.70 & 0.41 & 0.54 \\
WGA331 & Dangl et al. (2005) & 5 & 0.58 & 0.61 & 0.61 \\
WGA332 & Dangl et al. (2005) & 6 & 0.68 & 0.74 & 0.58 \\
WGA349 & Dangl et al. (2005) & 8 & 0.55 & 0.59 & 0.76 \\
WGA376 & Dangl et al. (2005) & 10 & 0.52 & 0.62 & 0.80 \\
Average & & 6.43 & & & 0.68 \\
\hline
\end{tabular}

PIC, polymorphic information content; SSR, simple sequence repeats. 


\section{RESULTS AND DISCUSSION}

The genotypes and standard cultivars used in this study were not previously subjected to molecular characterisation. The co-dominant inheritance and the distribution throughout the genome provide easy manipulation and large allelic variation making microsatellite analysis the optimal method for assessing genetic diversity (Suprun et al., 2013). The genetic diversity analysis of walnut landraces and standard cultivars included the average number of alleles per locus $(n)$, expected heterozygosity $\left(H_{\mathrm{e}}\right)$, observed heterozygosity $\left(H_{\mathrm{o}}\right)$ and PIC (Table 2 ). The selected SSR loci provided a great resolution in evaluating the genetic relationship of local walnuts due to their rich allelic diversity and co-dominance.

In total, 135 alleles were obtained from the $21 \mathrm{SSR}$ loci analysed. Results show that the number of alleles per locus ranged from 3 (WGA027) to 11 (WGA276) with a mean number of 6.43 alleles per locus (Table 2). Along with WGA276 locus, WGA376 (with 10 alleles per locus) and WGA054 (with 9 alleles per locus) yielded the highest number of alleles (Table 2). WGA027, WGA071 and WGA079 gave the lowest alleles per locus (Table 2). Walnut cultivars and landraces originating from different parts of the world were previously characterised by SSR analysis. Ruiz-Garcia et al. (2011) used 57 common walnut cultivars, mainly from Spain and the USA, in SSR analysis. They obtained a total of 97 alleles and an average of 5 alleles per locus. Their study obtained the highest number of alleles per locus from WGA032 (10 alleles per locus) and WGA227 (9 alleles per locus), which is in accordance with our results. Khokhlov et al. (2018) used 15 walnut cultivars from Ukraine for SSR analysis and found that the number of alleles per locus ranged from 5 (WGA69) to 13 (WGA276), with an average of 8 alleles per locus indicating a high degree of polymorphism and a high genetic diversity within samples. In the characterisation of 44 walnut genotypes by 14 microsatellite loci reported by Dangl et al. (2005), the number of alleles per locus ranged from 3 to 8 with an average of 5.2. Karimi et al. (2010) studied diversity of natural populations of $J$. regia in Iran using 11 SSR loci and obtained 5.7 alleles per locus. Kim et al. (2012) analysed 8 Korean and 12 foreign walnut cultivars using 12 SSR primer pairs and they obtained an average of 9.6 alleles per locus. Pop et al. (2013) used seven SSR loci to characterise 20 walnut cultivars and reported 6.7 alleles per locus. The high level of variability observed from 21 SSR loci is consistent with the results from the aforementioned studies. In Iran, Mahmoodi et al. (2013) used 16 walnut accessions and 5 cultivars for molecular characterisation. They used 9 SSR markers and reported that the number of alleles per locus ranged from 2 (WGA71) to 7 (WGA202) with a mean of 4.25. In another study conducted in Iran, Vahdati et al. (2015) analysed 6 walnut populations using 17 microsatellite loci and found the number of alleles per locus ranging from 4 to 11, with a total of 147 alleles and an average of 5.16 alleles per locus. Our results confirm that the markers used in our study are suitable for walnut genetic identification. Ehtesham-Nia et al. (2009), Aradhya et al. (2010), Ebrahimi et al. (2011) and Dogan et al. (2014) reported that the highest number of alleles was generated by WGA202, WGA276 and WGA376 loci in walnut cultivars. They also reported that WGA027 locus gave the lowest numbers of alleles. The polymorphism level revealed by the SSR markers can depend on genetic and phylogenetic distance within the genotypes due to their outcrossing nature.

The expected and observed heterozygosities were found to be between 0.49 (WGA027) and 0.80 (WGA118), and 0.41 (WGA225) and 0.80 (WGA005), respectively (Table 2). The average expected and observed heterozygosities were found as 0.62 and 0.60 , respectively. Results clearly indicate that our seed-propagated outcrossing walnut genotypes have shown a high degree of heterozygosity. Victory et al. (2006) reported a high observed heterozygosity value (higher than 0.80) of wild Juglans nigra population using SSR markers, which could be explained by the outcrossing nature of wild black walnut. Khokhlov et al. (2018) reported observed heterozygosity from 0.50 in WGA349 to 0.88 in WGA202 and WGA376 with an average of 0.73 . Ruiz-Garcia et al. (2011) obtained observed heterozygosity between 0.23 (WGA079) and 0.74 (WGA05). Mahmoodi et al. (2013) obtained the highest observed heterozygosity from WGA5 and WGA32 primers and reported observed heterozygosity as 0.62 and expected heterozygosity as 0.63 , which is in accordance with our results. Balapanov et al. (2019) used 62 walnut samples from the collections of the Nikita Botanical Gardens, North Caucasian Federal Science Center of Horticulture Viticulture \& Winemaking (NCFSCHVW), a private Moldovan collection, and analysed them with 11 microsatellite loci. They found that 11 SSR markers have showed a high level of polymorphism, and observed heterozygosity that was between 0.44 and 0.86 with an average value of 0.67 which was lower than the expected heterozygosity for all loci, with the exception of WGA376. In Iran, Vahdati et al. (2015) analysed 6 walnut populations using 17 microsatellite loci and reported 0.65-0.87 expected heterozygosity for the populations.

PIC refer to the value of a marker for detecting polymorphism within a population, depending on the number of detectable alleles and the distribution of their frequency; thus, it provides an estimate of the discriminating power of the marker and therefore the PIC values were calculated for all primers (Table 2). The average PIC value was obtained as 0.68 . The most informative locus was WGA276 (0.85), followed by WGA202 (0.83), WGA376 (0.80) and WGA089 (0.79), whereas the least informative loci were WGA321 (0.54), WGA004 (0.55) and WGA079 (0.55). According to our results, 13 loci are classified as informative markers $(\mathrm{PIC}>0.5)$ and 8 loci as suitable for mapping $(\mathrm{PIC}>0.7)$ (Table 2). These results indicate that all the markers could 
provide valuable information on walnut genetics and breeding research. The results also show that the walnut populations of Kagizman district have relatively high levels of genetic diversity. Pollegioni et al. (2011) observed that except WGA004 (0.355) and WGA331 (0.382), all markers had PIC $>0.50$. Vahdati et al. (2015) analysed 6 walnut populations from Iran using 17 microsatellite loci and found that PIC for the loci ranged from 0.56 to 0.82 with an average of 0.72 . The PIC measure is an important component in the planning of breeding programmes, and it is a key information element and statistical indicator (Chesnokov and Artemyeva, 2015).

The genetic relationship between the genotypes was clearly depicted in the dendrogram that was constructed from the DNA profile. The dendrogram was obtained after processing the experimental data. The dendrogram divided the analysed sample into two large clusters, indicating the heterogeneity of the seed-propagated walnut genotypes in the Kagizman district in Turkey. The node separating cluster I from cluster II had a high bootstrap value indicating high variation between the genotypes in clusters I and II (Figure 1).
The first cluster consisted of 10 seed-propagated genotypes and 2 standard cultivars. Within the first cluster, two subgroups were formed. The first subgroup included 10 seed-propagated genotypes. The second subgroup consisted of two seed-propagated genotypes and two standard cultivars. The closest genotypes in the first cluster were KW18 and KW31 with 0.83 similarity ratio. KW18 and $\mathrm{KW} 31$ have some morphological similarities such as semi upright growth habit, medium tree vigour, similar nut weight and light amber kernel colour (Figure 1). It is worth noting that KW18 and KW31 showed less diversity suggesting homogeneity and genetic flux or common origin. Within cluster I, cvs. 'Bilecik' and 'Sebin' were grouped together with 0.55 similarity ratio. 'Bilecik' and 'Sebin' were closely clustered with the seed-propagated genotypes (KW10 and KW24). This could be explained by the presence of a common genetic origin among the genotypes/cultivars despite their great diversity. The second cluster consisted of 20 seed-propagated genotypes and further divided into 2 subgroups. Within cluster II, the first subgroup included 12 genotypes and the second subgroup

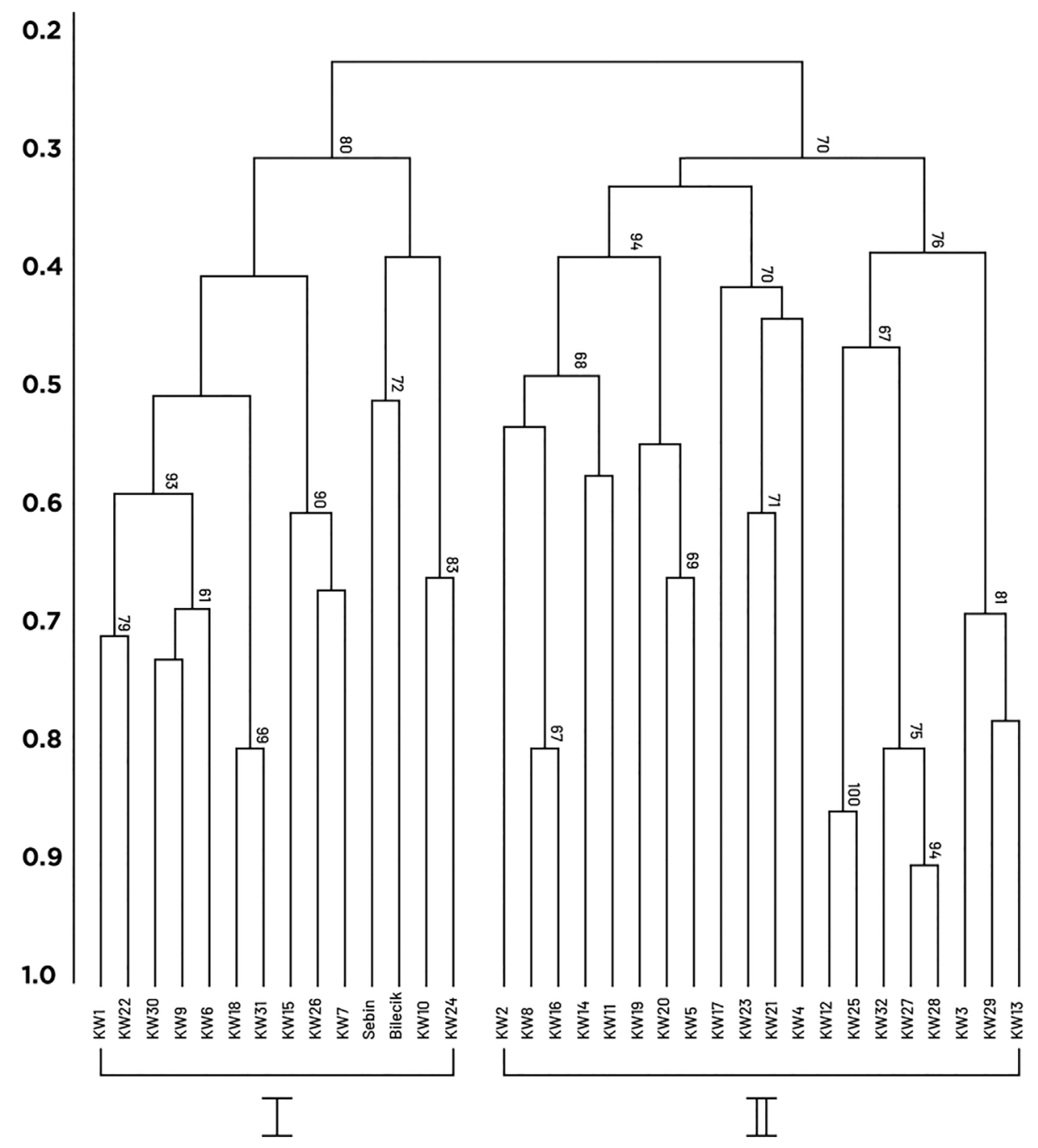

Figure 1. The UPGMA dendrogram based on simple matching similarity matrix obtained using 21 SSR markers, illustrating the relative similarity among 32 walnut genotypes and 2 standard cultivars. 
contained 8 genotypes. Genotypes KW27 and KW28 were the closest with 0.87 similarity ratio, while KW29 and KW22 were the most distant with 0.23 similarity ratio (Figure 1). KW27 and KW28 show some similar morphological characteristics. Both genotypes have lateral bearing habit, strong tree vigour, similar kernel ratio and light kernel colour. The SSR similarity level found between KW27 and KW28 indicates a common or related ancestry. In addition, the genotypes that have upright growth habit (KW2, KW13, KW17, KW25 and KW32) except KW9 were assigned in cluster II. Certain degree of relationship between walnut genotypes is probably related to their seed-propagated nature.

According to these results, we could infer that the 34 walnut genotypes/cultivars are divergent. The characteristics of seed-propagated walnuts in relation to the magnitude of allelic and genetic diversity in contrast to cultivars are considered to be significantly more genetically diverse. Thus, a seed-propagated walnut genotype is highly variable in appearance and highly genetically diverse or genetically heterogeneous. They are recognised as a distinct entity via common-shared traits. These traits will allow the distinction of one seedpropagated genotype from another or from modern cultivars for the same crop (Sutyemez, 1998; Şimsek, 2010).

There were some similarities between morphological traits and molecular data. The genotypes assigned in cluster I have semi upright growing habits, lateral bearing, medium tree vigour and late bud-breaking characteristics (Figure 1). However, the genotypes in cluster II also have the above-mentioned morphological traits. All genotypes and two cultivars examined in this study are seed-propagated and with unknown parentage.

Such a wide interval of similarity values indicates a wide range of genetic diversity of the analysed walnut genotypes. The seedling-originated genotypes also affect the present results. About 5 million walnut trees in Turkey are composed generally of non-grafted trees, thus increasing the genetic variation of walnut germplasm and offering an opportunity for breeders to select the best genotypes. Genotypes collected from various parts of Kagizman district showed diverse clustering which could be due to the outcrossing nature of walnut. Ahmed et al. (2012) reported similarity between 0.12 and 0.78 with average of 0.49 in walnut through SSR analysis. Dogan et al. (2014) reported genetic similarity values from 0.58 to 0.91 in walnut cultivars from Turkey.

PCA was applied to the raw data from the SSR ' 1 ' and ' 0 ' matrix by using NTSYS 2.10 e software, and the contribution rates of the first 3 principal coordinates were $34.44 \%, 27.15 \%$ and $12.80 \%$, respectively, accounting for $74.39 \%$ of the genetic similarity variance. These walnut genotypes/cultivars samples were partitioned into two distinct groups. PCA Group 1 included 12 samples, and PCA Group 2 included 19 samples (Figure 2) which was in general consistent

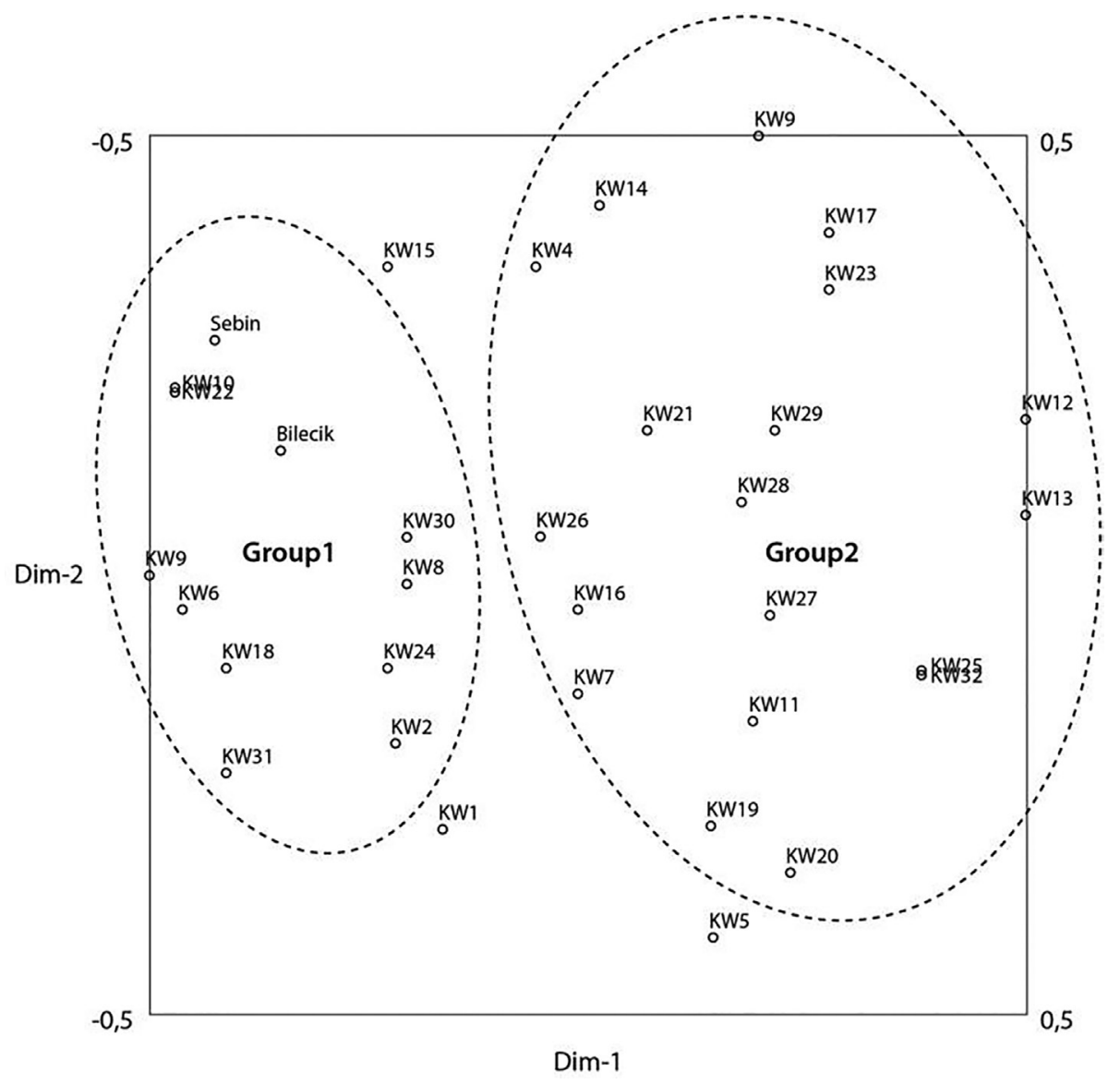

Figure 2. Two-dimensional PCA of 34 individual walnut genotypes/cultivars. 
with the cluster analysis output. PCA1 appeared to be much more informative, clearly separating two different groups. The genetic variation was higher in Group 2 than in Group 1. The markers employed in this study will be useful for the characterisation and comparison of walnut germplasm collections and for the detection of propagation errors. The evaluation of the molecular diversity of walnut genetic resources is important for optimal programme development aiming conservation. These markers were able to identify uniquely all the tested walnut genotypes.

\section{CONCLUSION}

Detailed characterisation of plant genetic structure is a vital step of a breeding programme, together with efficient protection and use of plant genetic resources. Molecular marker analysis is considered as the most reliable and powerful method for such characterisation. To date, only a limited number of studies have examined the genetic relationships between seed-propagated walnuts using SSR-based approach. Understanding genetic variation and relationships within genotypes and standard cultivars is crucial for fundamental research, conservation and the potential utilisation of genetic resources for walnut breeding. The results of this study demonstrated that genetic diversity exists between the investigated walnut genotypes. SSRs revealed a high mean number of alleles per locus, as well as a high heterozygosity and PIC values. The study outputs indicated that SSR markers can be successfully used to determine the diversity of seed-propagated walnut genotypes. Genetic variations among seed-propagated walnut genotypes could be useful in selecting parents to be crossed to generate suitable populations intended for breeding strategies. The information provided by this research will shed light on future studies of walnut cultivar selection, planting and production.

\section{AUTHOR CONTRIBUTIONS}

E.O. and S.P.E. executed the study and drafted the manuscript. D.P., M.A. and T.W. helped with data analysis interpretation and writing the manuscript. S.E. supervised the study and edited the manuscript.

\section{CONFLICT OF INTEREST}

The authors declare that there are no potential conflicts of interest regarding the research, authorship and publication of this manuscript.

\section{REFERENCES}

Ahmed, N., Mir, J. I., Mir, R. R., Rather, N. A., Rashid, R., Wani, S. H., Shafi, W., Mir, H., and Sheikh, M. A. (2012). SSR and RAPD analysis of genetic diversity in walnut (Juglans regia L.) genotypes from Jammu and Kashmir, India. Physiology and Molecular Biology of Plants, 18(2), 149-160.
Aradhya, M., Woeste, K., and Velasco, D. (2010). Genetic diversity, structure and differentiation in cultivated walnut (Juglans regia L.). Acta Horticulturae, 861, 127-132.

Balapanov, I., Suprun, I., Stepanov, I., Tokmakov, S., And Lugovskoy, A. (2019). Comparative analysis Crimean, Moldavian and Kuban Persian walnut collections genetic variability by SSR-markers. Scientia Horticulturae, 253, 322-326.

Balci, I., Balta, F., Kazankaya, A., and Sen, S. M. (2001). Promising native walnut genotypes (Juglans regia L.) of the east Black Sea region of Turkey. Journal of the American Pomological Society, 55, 204-208.

Bayazit, S., Kazan, K., Gulbitti, S., ÇeviK, V., Ayanoglu, H., And Ergul, A. (2007). AFLP analysis of genetic diversity in low chill requiring walnut (Juglans regia L.) genotypes from Hatay, Turkey. Scientia Horticulturae, 111, 394-398.

Bennett, E. (1970). Adaptation in wild and cultivated plant populations. In O.H. Frankel and E. Bennett (Eds.), Genetic resources in plants-their exploration and conservation (pp. 115-129). International Biological Programme Handbook No. 11. Oxford, UK: Blackwell.

Bernard, A., Barreneche, T., Lheureux, F., And Dirlewanger, E. (2018). Analysis of genetic diversity and structure in a worldwide walnut (Juglans regia L.) germplasm using SSR markers. PLoS ONE, 13(11), e0208021.

Bowcock, A. M., Ruiz-Linares, A., Tomfohrde, J., Minch, E., Kidd, J. R., And Cavalli-Sforza, L. L. (1994). High resolution of human evolutionary trees with polymorphic microsatellites. Nature, 368, 455-457.

Chen, L., Qingguo, M., Chen, Y. K., Wang, B. Q., And PEI, D. (2014). Identification of major walnut cultivars grown in China based on nut phenotypes and SSR markers. Scientia Horticulturae, 168, 240-248.

Chesnokov, Y. V., And Artemyeva, A. (2015). Evaluation of the measure of polymorphism information of genetic diversity. Agricultural Biology, 50, 571-578.

Ciarmiello, L. F., Piccirillo, P., Pontecorvo, G., Luca, A. D., Kafantaris, I., And Woodrow, P. (2011). A PCR based SNPs marker for specific characterization of English walnut (Juglans regia L.) cultivars. Molecular Biology Reports, 38, 1237-1249.

Dang, M., Zhang, T., Hu, Y., Zhou, H., Woeste, K. E., And Zhao, P. (2016). De novo assembly and characterization of bud, leaf and flowers transcriptome from Juglans regia $\mathrm{L}$. for the identification and characterization of new ESTSSRs. Forests, 7, 247.

Dangl, G. S., Woeste, K., Aradhya, M. K., Koenmstedt, A., Simon, C., Potter, D., Leslie, C. A., and Mcgranahan, G. (2005). Characterization of 14 microsatellite markers for genetic analysis and cultivar identification of walnut. Journal of the American Society for Horticultural Science, 130, 348-354. 
Dogan, Y., Kafkas, S., Sutyemez, M., Akca, Y., And Turemis, N. (2014). Assessment and characterization of genetic relationships of walnut (Juglans regia L.) genotypes by three types of molecular markers. Scientia Horticulturae, 168, 81-87.

Ebrahimi, A., FAtahi, R., And Zamani, Z. (2011). Analysis of genetic diversity among some Persian walnut genotypes (Juglans regia L.) using morphological traits and SSRs markers. Scientia Horticulturae, 130, 146-151.

Ehtesham-Nia, A., Sharifani, M., Vahdati, K., And Erfani-Moghaddam, V. (2009). Investigation of genetic diversity among some native populations of walnut (Juglans regia L.) in Golestan province by SSR markers. Iran Journal of Plant Production, 16, 39-58.

ERcisli, S., IpeK, A., AND BARUt, E. (2011). SSR markerbased DNA fingerprinting and cultivar identification of olives (Olea europaea). Biochemical Genetics, 49(9-10), 555-561.

Ercisli, S., Orhan, E., Esitken, A., Yildirim, N., AND Agar, G. (2008). Relationships among some cornelian cherry genotypes (Cornus mas L.) based on RAPD analysis. Genetic Resources and Crop Evolution, 55(4), 613-618.

Ercisli, S., Sayinci, B., Kara, M., Yildiz, C., And Ozturk, I. (2012). Determination of size and shape features of walnut (Juglans regia L.). Scientia Horticulturae, 133, 47-55.

ERIKSSON, G. (1998). Sampling for genetic resources population in the absence of genetic knowledge. In Noble Hardwoods Network, Report of the second meeting, Euforgen, IPGRI, pp. 61-75.

Ertürk, Ü., Mert, C., Soylu, A., AkÇa, Y., and Okay, Y. (2014). Evaluation of some domestic and foreign walnut cultivars in the conditions of Bursa, Turkey. Acta Horticulturae, 1050, 123-130.

Eyduran, S. P., Ercisli, S., Akin, M., and Eyduran, E. (2016). Genetic characterization of autochthonous grapevine cultivars from Eastern Turkey by simple sequence repeats (SSRs). Biotechnology \& Biotechnological Equipment, 30, 26-31.

FAO. (2018). Food and Agriculture Organization of the United Nation Statistics for 2018. Retrieved from http://www.fao.org/faostat/en/\#home; cited on 10 September 2019.

Foroni, I., Woeste, K., Monti, L. M., and Rao, R. (2007). Identification of 'Sorrento' walnut using simple sequence repeats (SSRs). Genetic Resources and Crop Evolution,. 54(5), 1081-1094.

Guney, M., Kafkas, S., Keles, H., Aras, S., And Ercisli, S. (2018). Characterization of hawthorn (Crataegus spp.) genotypes by SSR markers. Physiology and Molecular Biology of Plants, 24(6), 1221-1230.

Guney, M., Kafkas, S., Koç, A., Aras, S., Keles, H., And KARCI, H. (2019). Characterization of quince (Cydonia oblonga Mill.) accessions by SSR markers. Turkish Journal of Agriculture and Forestry, 43, 69-79.
IPGRI (1994). Descriptors for walnut (Juglans spp.). Rome, Italy: International Plant Genetic Resources Institute.

Kafkas, S., Ozkan, H., and Sutyemez, M. (2005). DNA polymorphism and assessment of genetic relationships in walnut genotypes based on AFLP and SAMPL markers. Journal of the American Society for Horticultural Science, 130, 585-590.

Kalinowski, S. T., Taper, M. L., And Marshall, T. C. (2007). Revising how the computer program CERVUS accommodates genotyping error increases success in paternity assignment. Molecular Ecology, 16(5), 1099-1106.

Karimi, R., Ershadi, A., Vahdati, K., and Woeste, K. (2010). Molecular characterization of Persian walnut populations in Iran with microsatellite markers. Horticultural Science, 45, 1403-1406.

Keles, H., Aкca, Y., And Ercisli, S. (2014). Selection of promising walnut genotypes Juglans regia L from inner Anatolia. Acta Scientiarum Polonorum Hortorum Cultus, 13(3), 167-175.

Khokhlov, S., Panyushina, E., Balapanov, I., Suprun, I., AND ToKmaKov, S. (2018). Identification of walnut cultivars from Nikita Botanical Gardens using SSR-markers. Acta Horticulturae, 1208, 47-52.

Kim, H. B., Jeon, J. H., Han, A. R., Lee, Y., Jun, S. S., KIM, T. H., ChO, G. H., AND PARK, P. B. (2012). Genetic evaluation of domestic walnut cultivars trading on Korean tree markets using microsatellite markers. African Journal of Biotechnology, 11, 7366-7374.

Kirca, S., Yarilgaç, T., Kirca, L., and BaK, T. (2014). Study on the selection of walnut (Juglans regia $\mathrm{L}$.) in Trabzon. Turkish Journal of Agricultural and Natural Sciences, 1, 835-841.

Mahmoodi, R., Rahmani, F., and Rezaee, R. (2013). Genetic diversity among Juglans regia L. genotypes assessed by morphological traits and microsatellite markers. Spanish Journal of Agricultural Research, 11(2), 431-437.

Martinez, M. L., Labuckas, D. O., Lamarque, A. L., And Maestri, D. M. (2010). Walnut (Juglans regia L.): Genetic resources, chemistry, by-products. Journal of the Science of Food and Agriculture, 90, 1959-1967.

Martinez-Garcia, P. J., Crepeau, M. W., Puiu, D., Gonzalez-Ibeas, D., Whalen, J., Stevens, K. A., Paul, R., Butterfield, T. S., Britton, M. T., Reagan, R. L., Chakraborty, S., Walawage, S. L., VasquezGross, H. A., Cardeno, C., Famula, R. A., Pratt, K., Kuruganti, S., Aradhya, M. K., Leslie, C. A., Dandekar, A. M., Salzberg, S. L., Wegrzyn, J. L., Langley, C. H., And Neale, D. B. (2016). The walnut (Juglans regia) genome sequence reveals diversity in genes coding for the biosynthesis of non-structural polyphenols. The Plant Journal, 87, 507-532.

Minch, E., Ruiz-Linares, A., Goldstein, D. B., Feldman, M., and Cavalli-Sforza, L. L. (1995). Microsat (Version 1.4d): a computer program for calculating 
various statistics on microsatellite allele data. Stanford, USA: Stanford University Medical Center.

NeI, M., AND LI, W. H. (1979). Mathematical model for studying genetic variation in terms of restriction endonucleases. Proceedings of the National Academy of Sciences of the USA, 76, 5269-5273.

Olez, H. (1976). Selection of walnuts from Marmara region in Turkey. Horticulture Research and Education Center, 4, 4.

Paetkau, D., Calvert, W., Stirling, I., and Strobeck, C. (1995). Microsatellite analysis of population structure in Canadian polar bears. Molecular Ecology, 4, 347-354.

Pavlicek, A., Hrda, S., And Flegr, J. (1999). FreeTreesoftware program for construction of phylogenetic trees on the basis of distance data and bootstrapping jack-knife analysis of the tree robustness. Application in the RAPDs analysis of the genus Frenkelia. Folia Biologica (Praha), 45, 97-99.

Poczai, P., Varga, I., Laos, M., Cseh, A., Bell, N., Valkonen, J. P., And Hyvönen, J. (2013). Advances in plant gene-targeted and functional markers: A review. Plant Methods, 9(6), 1-31.

Pollegioni, P., Woeste, K., Olimpieri, I., Marandola, D., Cannata, F., and Malvolti, M. E. (2011). Long term human impacts on genetic structure of Italian walnut inferred by SSR markers. Tree Genetics and Genomes, 7, 707-723.

Pop, I. F., Vicol, A. C., Botu, M. R., Paul, A. R., Vahdati, K., and Pamfil, D. (2013). Relationships of walnut cultivars in a germplasm collection: Comparative analysis of phenotypic and molecular data. Scientia Horticulturae, 153, 124-135.

Potter, D., Gao, F., Aiello, G., Leslie, C., And McGranahan, G. (2002). Inter simple sequence repeat markers for fingerprinting and determining genetic relationships of walnut (Juglans regia). J. Amer. Soc. Hort. Sci. 127, 75-81.

Ruiz-garcía, L., Ortega, G. L., Denia, A. F., And FRUTOS, D. (2011). Identification of a walnut (Juglans regia $\mathrm{L}$.) germplasm collection and evaluation of their genetic variability by microsatellite markers. Spanish Journal of Agricultural Research, 9(1), 179-192.

ŞIMSEK, M. (2010). Selection of walnut types with high fruit bearing and quality in Sanliurfa population.
International Journal of Physical Sciences, 5, 992-996.

Sneath, P. H., and Sokal, R. R. (1973). Numerical taxonomy. San Francisco, USA: Freeman.

Suprun, I. I., Tokmakov, S. V., Stepanov, I. V., And Balapanov, I. M. (2013). Development of multiplex SSRmarker sets for use in the study of genetic diversity within the genera Malus, Prunus and Pyrus, in Metodologicheskoe obespechenie selektsii sadovykh kul'tur i vinograda na sovremennom etape (Methodological Support of Horticultural Crops and Grapes Breeding at the Current Stage), Nauchn. Tr. Severo-Kavkaz. Zonal. Nauchno-Issled. Inst. Sadov. Vinograd., Krasnodar, 2013, Vol. 1, pp. 97-101.

Sutyemez, M. (1998). Selection of seed propagated walnuts (Juglans regia L.) from Kahramanmaraş region ad studies on fertilization biology of selected genotypes ( $\mathrm{PhD}$ Thesis). Cukurova University, Turkey, p. 201.

Sutyemez, M. (2006). Comparison of AFLP polymorphism in progeny derived from dichogamous and homogamous walnut genotypes. Pakistan Journal of Biological Sciences, 9, 2303-2307.

Vahdati, K., Pourtaklu, S. M., Karimi, E., BarzehKar, R., Amiri, R., Mozaffari, M., And Woeste, K. (2015). Genetic diversity and gene flow of some Persian walnut populations in southeast of Iran revealed by SSR markers. Plant Systematics and Evolution, 301(2), 691-699.

Victory, E. R., Glaubitz, J. C., Rhodes, O. E., and Woeste, K. E. (2006). Genetic homogeneity in Juglans nigra (Juglandaceae) at nuclear microsatellites. American Journal of Botany, 93, 118-126.

Villa, T. C. C., Maxted, N., Scholten, M., and FordLloyd, B. (2006). Defining and identifying crop landraces. Plant Genetic Resources, 3(3), 373-384.

Wagner, H. W., and SefC, K. M. (1999). Identity 1.0. centre for applied genetics. Vienna, Austria: University of Agricultural Science.

Woeste, K., Burns, R., Rhodes, O., and Michler, C. (2002). Thirty polymorphic nuclear microsatellite loci from black walnut. Journal of Heredity, 93, $58-60$

Received October 29, 2019; accepted January 13, 2020 